\title{
Preparation of low-cost foam ceramics with mullite extracted from fly ash
}

\author{
Saishengtai GAO ${ }^{1,2}$, Yongfeng ZHANG ${ }^{1, \dagger}$ and Yinmin ZHANG ${ }^{1}$ \\ ${ }^{1}$ School of Chemical Engineering, Inner Mongolia University of Technology, Hohhot 010051, China \\ ${ }^{2}$ Department of chemical engineering, Inner Mongolia Vocational College of chemical Engineering, Hohhot 010070, China
}

\begin{abstract}
Foam ceramic materials with uniform pore structure were prepared by adopting organic foam impregnation method using mullite $(0.045-0.075 \mathrm{~mm})$ extracted from fly ash as raw materials, aluminum dihydrogen phosphate and kaolin $(0.045-0.088 \mathrm{~mm})$ as bonding reagent and plasticizer, respectively. The influence of phosphate content, solid (mullite and kaolin) content and ball-milling time on performance of mullite slurry has been investigated. Especially, the relationship between various properties of the slurry and obtained foam ceramics have been discussed. Furthermore, the physical properties and sintering behaviors of the as-prepared samples at different temperatures were systematically investigated. The result indicated that a high-quality slurry with low sedimentation degree, suitable viscosity and small particle $D_{50}$ can be prepared under the condition of phosphate content of 12.5 mass \%, solid phase content of 62 mass \% and ball milling time of $8 \mathrm{~h}$. Finally, the mullite foam ceramic products with a compressive strength of $1.62 \mathrm{MPa}$, an apparent porosity of $87 \%$ and a thermal shock resistance of 13 times were prepared after sintering at $1450{ }^{\circ} \mathrm{C}$ for $4 \mathrm{~h}$.

(c)2020 The Ceramic Society of Japan. All rights reserved.
\end{abstract}

Key-words : Foam ceramic, Mullite, Fly ash

[Received April 20, 2020; Accepted July 27, 2020]

\section{Introduction}

Coal fly ash is the unburned residue after the high temperature combustion of coal in thermal power plant. It is regarded as hazardous material all over the world, which presents serious problems related to storing and environmental pollution. ${ }^{1,2)}$ In view of demanding of the environmental protection and energy application, it is imperative to increase the utilization rate of massive fly ash. Since the main components of coal fly ash are silica $\left(\mathrm{SiO}_{2}\right)$ and alumina $\left(\mathrm{Al}_{2} \mathrm{O}_{3}\right)$, it is considered as a potential $\mathrm{Al}-\mathrm{Si}-\mathrm{O}$ material on the preparation of some industrial minerals such as zeolite, ${ }^{3)}$ glass ceramics, ${ }^{4)}$ foam glass, ${ }^{5)}$ and mullite ceramics. $^{6)-8)}$

Mullite ceramic has been extensively studied due to their excellent properties such as low thermal conductivity, moderate thermal expansion coefficient, low dielectric constant, sufficient mechanical strength and good chemical stability, it has been widely used in many fields. ${ }^{9)-11)}$ However, its application is restricted due to the expensive raw materials of alumina and silica. At present, to reduce their cost, most of the research focuses on the preparation of mullite ceramics using solid waste, especially the use of coal fly ash as raw materials. Fu et al. obtained highly porous whisker-structured mullite ceramic membranes

\footnotetext{
Corresponding author: Y. Zhang; E-mail: environzyf@sina com
}

derived from waste coal fly ash and $\mathrm{Al}(\mathrm{OH})_{3}$ as raw materials and $\mathrm{MoO}_{3}$ as a single sintering additive. ${ }^{12)} \mathrm{Li}$ et al. obtained ceramics with mullite whiskers from coal fly ash and $\mathrm{Al}_{2} \mathrm{O}_{3}$ raw materials, with $\mathrm{AlF}_{3}$ used as an additive after sintering at $1200^{\circ} \mathrm{C} .{ }^{13)} \mathrm{Ma}$ et al. prepared porous mullite ceramics from fly ash and bauxite via reaction synthesis process at firing temperature of 1450$1550{ }^{\circ} \mathrm{C} .{ }^{14)} \mathrm{Lu}$ et al. investigated the effect of alumina source on the densification, phase evolution and strengthening of sintered mullite-based ceramics from milled coal fly ash, and an optimal sintering temperature of $1100^{\circ} \mathrm{C}$ was identified. ${ }^{15)}$ Foo et al. synthesized mullite-based ceramics from coal fly ash and aluminum dross industrial wastes at sintering temperature of $1500^{\circ} \mathrm{C} .{ }^{16)}$ All these studies, however, require to add aluminum resources into fly ash for preparation of mullite ceramic. This is not conducive to the long-term development of mullite ceramics from an economic perspective due to scarcity bauxite resources in China. Furthemore, the high content of impurities in fly ash that have not been removed will affect the performance of mullite ceramics. ${ }^{17)}$

In northern China, about 100 million tons of fly ash were emission from thermal power plants annually, in which the alumina content reached up to 45 mass \% due to the rich kaolin in raw coal ${ }^{18)}$, X-ray diffraction (XRD) analysis shown that most of these compounds existed as mullite crystals with a content of 40.2 mass \%. ${ }^{19)}$ Herein, in order to prepare low-cost mullite ceramics on the 
premise of saving bauxite resources, we first extracted 82 mass $\%$ of mullite from the above-mentioned fly ash, and then used the extracted high content mullite prepares foam ceramics. This not only provides facilitate the recycling of coal fly ash but also saves bauxite resources which is relatively scarce in China.

In this contribution, we report a simple process for preparation of foam ceramics using high content of mullite extracted from coal fly ash as raw material by adopting organic foam impregnation method. In this process, aluminum dihydrogen phosphate and kaolin were used as bonding reagent and plasticizer, respectively. The influence of phosphate content, solid (mullite and kaolin) content and ball-milling time on performance of mullite slurry has been investigated. Especially, the relationship between various properties of the slurry and obtained foam ceramics have been discussed. The sintering behaviors of asprepared samples were also investigated in detail. From the view of cost effectiveness, the use of industrial waste fly ash without added aluminum resources for mullite ceramic preparation is very promising.

\section{Experimental}

\subsection{Raw materials}

The raw mullite with content of 82 mass $\%$ was extracted from coal fly ash after it was treated with magnetic separator, 20 mass \% of hydrochloric acid solution, 25 mass $\%$ of sodium hydroxide solution and dried at $105^{\circ} \mathrm{C}$ for $24 \mathrm{~h}$. The physical properties of mullite were mentioned in our previous reports. ${ }^{19)}$ The raw kaolin was purchased from kaolin plant located in Inner Mongolia, China. The morphology and characteristics of the kaolin were shown in Fig. 1 and Table 1, respectively. The kaolin contained 50.26 mass $\% \mathrm{SiO}_{2}$ and 48.09 mass $\% \mathrm{Al}_{2} \mathrm{O}_{3}$, determined by X-ray fluoroscopy analysis and consisted mainly of kaolin phase. Aluminum dihydrogen phosphate (Borui Chemical Co., China) was selected as the binder. Poly-

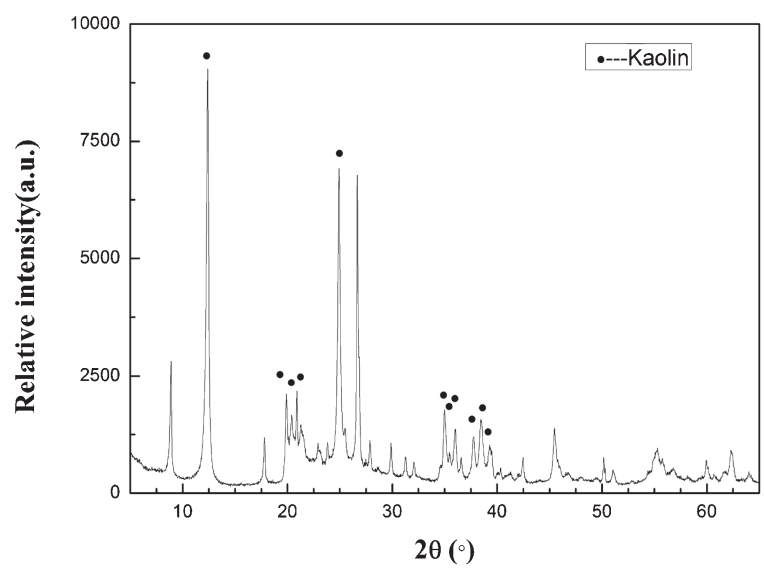

Fig. 1. The phase composition of kaolin.

Table 1. The chemical composition of kaolin (mass \%)

\begin{tabular}{ccccc}
\hline sample & $\mathrm{Al}_{2} \mathrm{O}_{3}$ & $\mathrm{SiO}_{2}$ & $\mathrm{Fe}$ & $\mathrm{TiO}_{2}$ \\
\hline kaolin & 48 & 50 & 0.25 & 0.2 \\
\hline
\end{tabular}

urethane (PU) reticulated foam material with a cell size of 10 pores per linear inch and $99 \%$ of porosity was chosen as the precursor of organic foam in this paper.

\subsection{Preparation method}

Firstly, eight pieces of PU foam with equal size were weighed and recorded respectively, then they were soaked in 20 mass $\%$ sodium hydroxide solution at $20^{\circ} \mathrm{C}$ for 0,1 , $2, \ldots 7 \mathrm{~h}$ to remove intermembrane, increase the surface roughness and improve hydrophilicity of foam, respectively. Before and after soaking, the PU substrate was rubbed repeatedly using water to wash off impurities and residual lye, then it was dried in a drying oven. Secondly, mullite, aluminum dihydrogen phosphate and kaolin mixed with distilled water in a certain ratio was added into the ball mill tank, then ball-milled for $8 \mathrm{~h}$ on a mill grinder. After milling, the slurry was uniformly coated on the PU reticulated foam and dried at $80^{\circ} \mathrm{C}$ for $24 \mathrm{~h}$, then took out and weighed. The hanging pulp amount of PU reticulated foam, which is expressed by the mass ratio of the organic foam after and before dipping slurry was calculated. The as-prepared solid phase dry embryo body was sintered in a muffle furnace at different temperatures at $1200,1300,1400,1450$ and $1500^{\circ} \mathrm{C}$ for $4 \mathrm{~h}$ respectively and cooled down naturally. Finally, white mullite foam ceramic products were obtained.

\subsection{Characterization}

The chemical compositions were examined by X-ray fluorescence spectrometer (XRF, X-calibure, Xenemetrix, America). The phase compositions were examined by XRD (D/MAX-2500/PC, Rigaku, Japan). The morphology of the samples were examined by scanning electron microscope and energy dispersive spectroscope (SEMEDS, SU8010, Hitachi, Japan). The fourier transform infrared spectros-copy (FTIR) were collected using NEXUS 670 (Nicolet, America) in the $4000-400 \mathrm{~cm}^{-1}$ region using potassium bromide as the diluents and binder. The rheology of the slurry was tested and characterized using the NDJ-76 rotary viscometer in the condition of 2 round per minutes at room temperature. The particle size distribution of powder and slurry were determined using a laser particle-size analyzer (Mastersizer 2000, Malvern Corporation, Britain). The stability of the slurry was characterized by the sedimentation degree (RSH) since standing for $24 \mathrm{~h}$ - the ratio of the height of water layer to the height of original slurry, the lower the RSH value of the slurry, the higher the stability.

The apparent porosity of foam ceramic samples were measured by a conventional method using Archimedes' principle in water medium. The number of times of thermal shock resistance was recorded after the foam ceramic samples was kept at $1100^{\circ} \mathrm{C}$ for $30 \mathrm{~min}$ in the electric furnace and then taken out and placed in flowing water at $20^{\circ} \mathrm{C}$ for $3 \mathrm{~min}$, and loop like this until it breaks. The strength test was carried out on a compression-testing machine, and each result was the average of five measurements with a deviation less than $10 \%$. 


\section{Results and discussion}

\subsection{Effect of soaking time on weight loss rate and hanging pulp amount of the foam body}

$\mathrm{PU}$ is a general term for a class of polymers with repeating -NHCOO- groups on the main chain prepared by the reaction of polyol and polyisocyanate. Due to its special cross-linked structure and high resistance to common solvents, it is necessary to cause some defects on the surface of the PU and make it rough. The surface roughness of PU foam treated with sodium hydroxide solution is improved. This is because sodium hydroxide reacts with the surface of the PU foam to produce $-\mathrm{OH},{ }^{20}$ ) which makes the foam have good compatibility with water-based slurry. The reaction equation as follow (1):

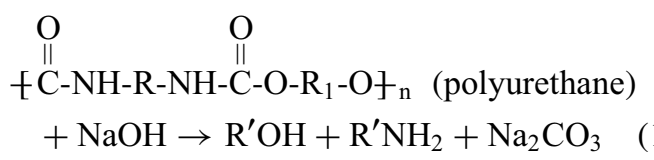

Figure 2(a) shows the influence of soaking time on weight loss rate of PU foam. It can be seen that the weight loss rate of foam increased slowly before $3 \mathrm{~h}$ and quickly between $3-4 \mathrm{~h}$, it increased slowly $4 \mathrm{~h}$ later. The resilience
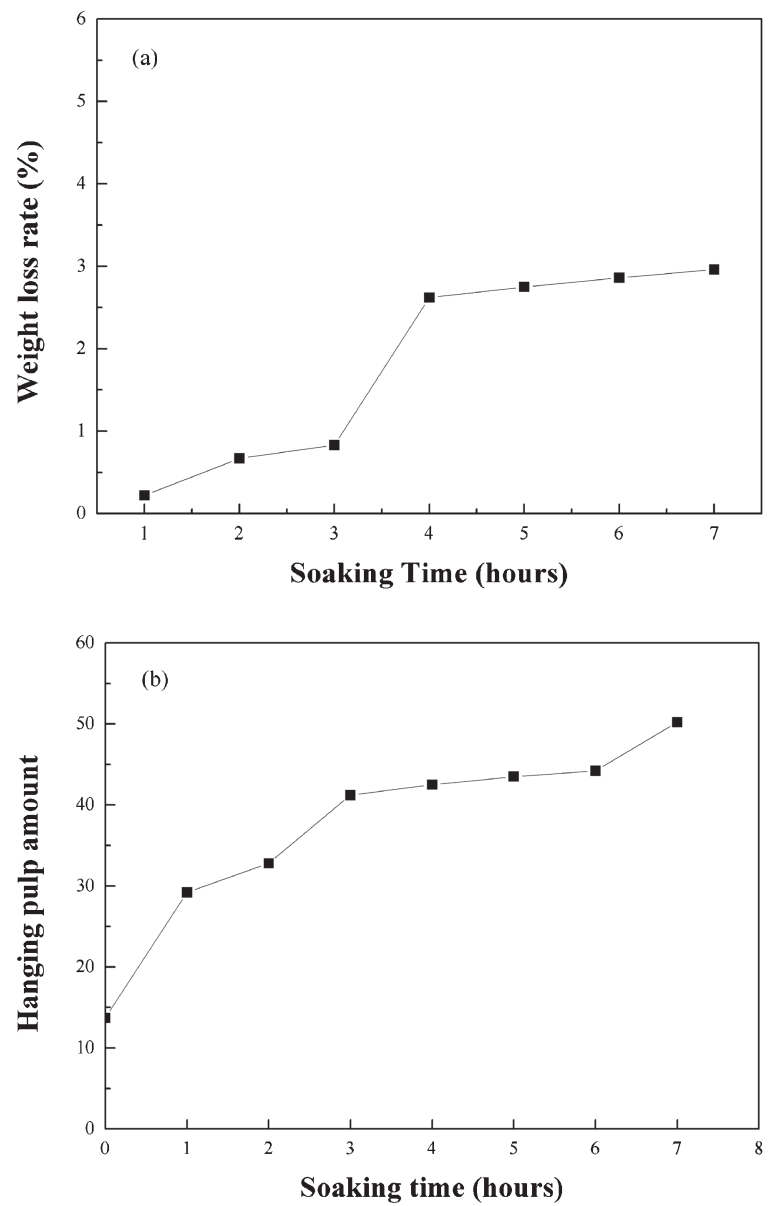

Fig. 2. Influence of soaking time on (a) weight loss rate and (b) hanging pulp amount of polyurethane foam. of PU foam was tested by a certain external force, the results shown that organic foam has good resilience when the soaking time less than $3 \mathrm{~h}$, while the resilience is poor when the soaking time exceeds $3 \mathrm{~h}$.

The influence of soaking time on hanging pulp amount of PU foam was displayed in Fig. 2(b). As can be seen, the hanging pulp amount increased significantly when the time ranged from 0 to $3 \mathrm{~h}$. While it increased slowly when the soaking time was higher than $3 \mathrm{~h}$. So the condition of 20 mass \% sodium hydroxide solution at $20^{\circ} \mathrm{C}$ for $3 \mathrm{~h}$ was adopt to pretreat PU foam. After pretreating, the surface of the organic foam body was corroded and the surface roughness was increased, and its hydrophilicity and adhesion performance were improved.

\subsection{Effect of ball-milling time on performance of mullite slurry}

Experiments were conducted at 62 mass \% $\quad(37.7$ volume $\%$ ) of solid content. The solid is composed of mullite and kaolin. Figure 3(a) shows the influence of ball-milling time range from 2 to $16 \mathrm{~h}$ on stability (RSH value) of the mullite slurry. As can be seen, the RSH value of the slurry decreases quickly with the increase of ballmilling time $(2-4 \mathrm{~h})$, while the relatively gentle decrease of RSH value from 12 to $5 \%$ was happen when ball-milling time increased from 4 to $8 \mathrm{~h}$. This is attributed to the decrease of the mullite particle size with the increase of ball-milling time leads to small gravity deposition, good dispersibility and stability of the slurry. When the ballmilling time was above $8 \mathrm{~h}$, the mullite slurry suspension system basically reached equilibrium state and the RSH value of the slurry remained substantially at about $5 \%$.

Figure 3(b) reveals the influence of ball-milling time on viscosity of the mullite slurry in the condition of 62 mass \% of solid content. As can be seen, with the increase of ball-milling time (2-16h), the viscosity of the slurry first quickly decreases then increases gradually. When ballmilling time was between $8-12 \mathrm{~h}$, the minimum viscosity value of slurry was obtained.

The whole change process of the mullite slurry viscosity may be the following reasons: in the initial stage $(2-8 \mathrm{~h})$, the movement resistance of the particles is large due to the big size of particle in the slurry, which leading to the high viscosity of slurry. As ball-milling time increasing (8$12 \mathrm{~h}$ ), the attraction and collision between the particles were reduced owing to the continuous refinement of mullite particles, thereby lowering the viscosity of the slurry. With the ball-milling time continue to increase $(12-20 \mathrm{~h}$ ), the phenomenon of "agglomeration" occurs between the particles due to the increase of surface bond force of the particles, resulting in a larger slurry viscosity. ${ }^{21)}$ Considering high viscosity of slurry will cause a serious problem of plugging and prone to cracks, while low viscosity of slurry with large fluidity was difficult to hang on the foam leading to low strength of foam ceramic, ${ }^{22)}$ so $8 \mathrm{~h}$ of ball-milling time has been chosen.

The influence of ball-milling time on $\mathrm{D}_{50}$ of mullite slurry particles in the condition of 62 mass $\%$ of solid 

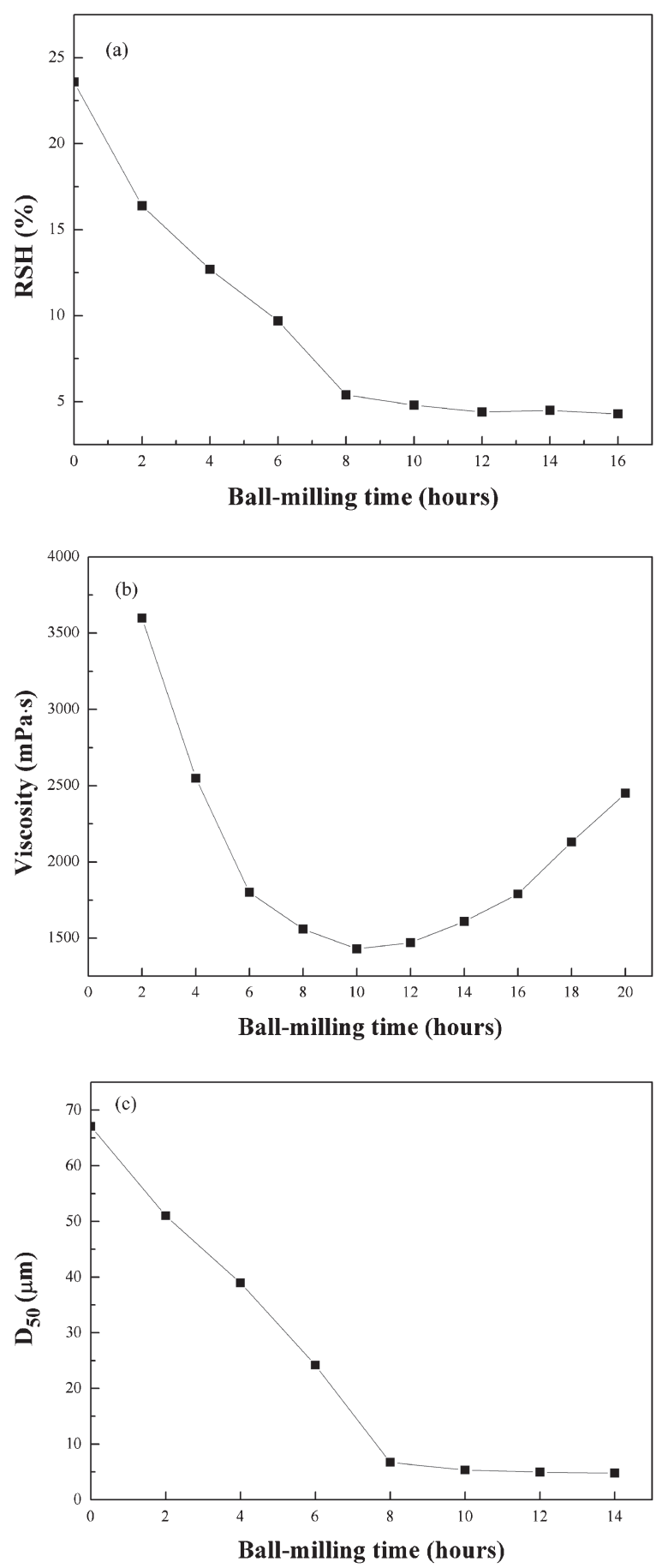

Fig. 3. Influence of ball-milling time on (a) RSH (b) viscosity (c) $\mathrm{D}_{50}$ of mullite slurry.

content was shown in Fig. 3(c). It can be seen from the figure that the $\mathrm{D}_{50}$ of the mullite particles decreased significantly from 67 to $7 \mu \mathrm{m}$ when the ball-milling time increase from 0 to $8 \mathrm{~h}$, while it almost has no change when the ball-milling time was higher than $8 \mathrm{~h}$.

3.3 Effect of slurry viscosity and $D_{50}$ on porosity and compressive strength of ceramic products

The influence of slurry viscosity on porosity and compressive strength of ceramic products was shown in
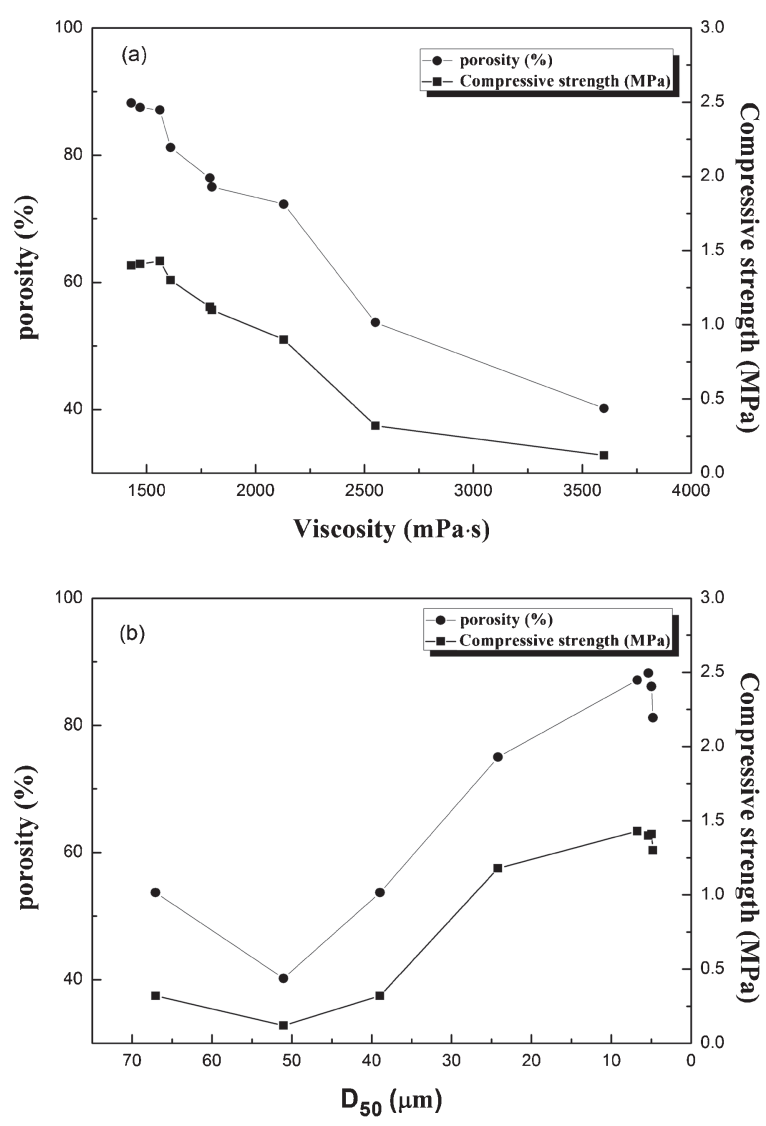

Fig. 4. Influence of (a) viscosity and (b) $\mathrm{D}_{50}$ of mullite slurry on porosity and compressive strength of foam ceramic.

Fig. 4(a). It can be seen that with the increase of slurry viscosity, the porosity and compressive strength of ceramic products decrease. This is attributed to generation of micro-cracks during the drying of the green body due to the uneven hanging slurry, which leads to a decrease in the porosity and compressive strength of ceramic products.

Figure $4(\mathrm{~b})$ shows the influence of slurry $\mathrm{D}_{50}$ on porosity and compressive strength of ceramic products. As can be seen, the porosity and compressive strength of ceramic products increase with the decrease of slurry $\mathrm{D}_{50}$. This is attributed to increase of proportion of finer grain boundaries due to the decrease of slurry $\mathrm{D}_{50}$, the initial crack will extend in the direction of the grain boundary when the material is damaged by external forces, the crack propagation path is longer than the non-fine-grained material, leading to the strength of the material greatly improved. Furthermore, combining Figs. 3(b) and 3(c), it can be seen that with the decrease of slurry $\mathrm{D}_{50}$, the slurry can uniformly coated on a PU reticulated foam due to its low viscosity, which leads to the increase of the porosity of ceramic products.

The optimal performance with low sedimentation degree, small particle size and right viscosity of mullite slurry was performed when the ball-milling time is $8 \mathrm{~h}$. Under this condition, the performance of the mullite foam ceramic prepared from this kind of slurry after sintering at $1450^{\circ} \mathrm{C}$ for $4 \mathrm{~h}$ was optimum. 


\subsection{Effect of solid content on performance of mullite slurry and foam ceramic}

The experiments solid content range is $40-75$ mass $\%$ (20-46.4 volume \%), ball-milling time is $8 \mathrm{~h}$, respectively. Figure 5(a) displays the influence of solid content on RSH of mullite slurry. As can be seen, the RSH value of the slurry decreased rapidly with the increase of solid content from 40 to 60 mass $\%$, while it has little changes when the solid content of mullite slurry was higher than 60 mass $\%$. This is because, as the solid content increases, the con-
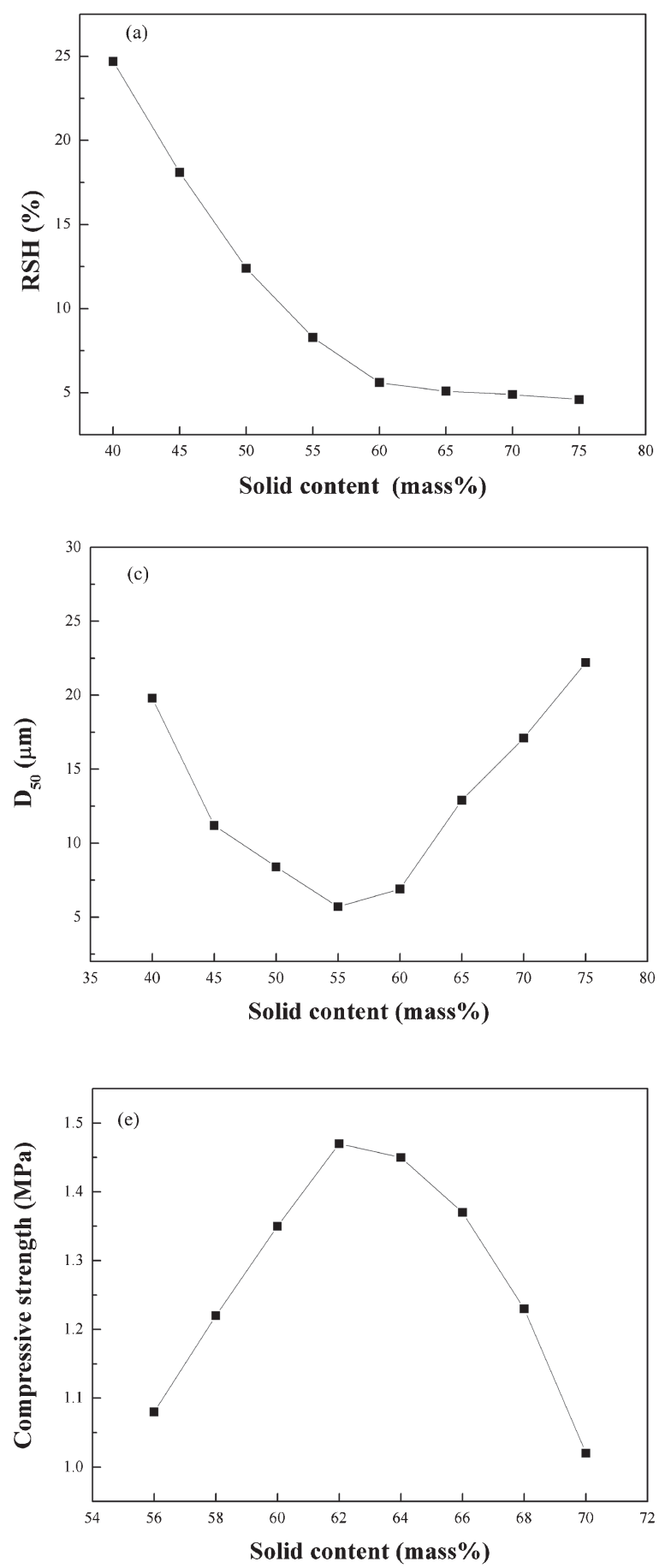

centration of suspended particles in the slurry increases, the stability of the slurry is increased due to the increased interference of adjacent solid particles during the sedimentation process. ${ }^{23)}$

Figure 5(b) reveals the influence of solid content on viscosity of mullite slurry in the condition of ball-milling time of $8 \mathrm{~h}$. The experimental results shows that the solid phase content has an important influence on viscosity of the slurry during slurry preparation process. With increasing of solid phase content, the change of the slurry viscos-
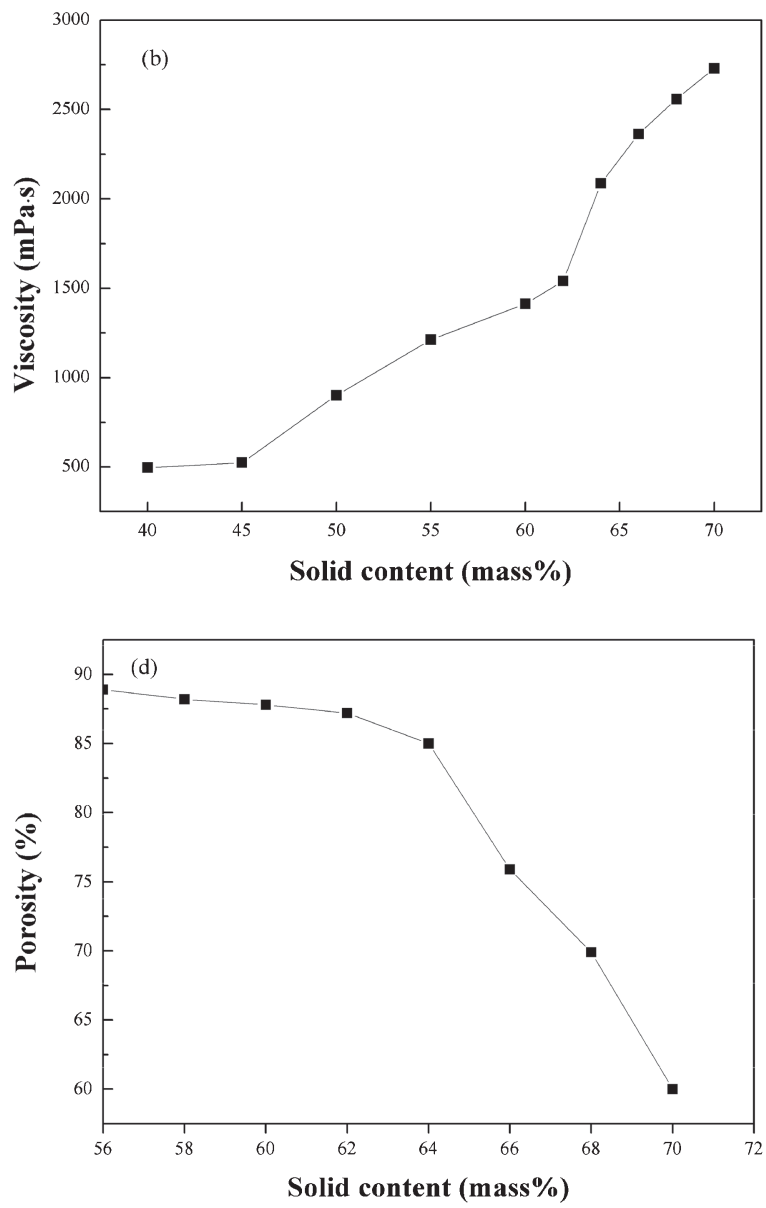

Fig. 5. Influence of solid content on (a) RSH (b) viscosity (c) $\mathrm{D}_{50}$ of mullite slurry and (d) porosity (e) compressive strength of foam ceramic. 
ity is small when the solid content is less than 62 mass \%. While the viscosity of the slurry rises sharply from 1500 to $2810 \mathrm{mPa} \cdot \mathrm{s}$ when the solid content increases from 62 to 70 mass $\%$.

The phenomenon that the slurry viscosity increases with the increase of the solid content can be explained by the Woodcook equation. ${ }^{24)}$ According to the Woodcook equation Eq. (2), with the increase of the solid content of the mullite slurry, the intermolecular force of particles increases due to the decreased spacing between the particles in the slurry. The flow resistance becomes greater, which leads to an increase in the viscosity of the ceramic slurry. In addition, as the solid phase content increases, the content of solvent in the slurry decreases, which also increases the viscosity of the slurry.

$$
\frac{h}{d}=\left(\frac{1}{3 \pi \varphi}+\frac{5}{6}\right)^{\frac{1}{2}}-1
$$

where $h$ is particle spacing, $d$ is particle diameter and $\varphi$ is the volume fraction of solid phase.

The influence of solid content on $\mathrm{D}_{50}$ of the mullite slurry particles in the condition of $8 \mathrm{~h}$ of ball-milling time was displayed in Fig. 5(c). The $\mathrm{D}_{50}$ of slurry particles firstly decreases and then increases with increasing of solid content (40-70 mass \%), the smallest $\mathrm{D}_{50}$ of slurry particles was presented when the solid content was 62 mass $\%$. This is because the collision increase between the spheres and the particles in the ball mill with the increase of solid content range from 40-60 mass \%, leading to the particles broken and the diameter gradually reduced. However, the adsorption agglomeration between the particles was increased due to the increasing of surface bond force when solid content is above 62 mass \%, resulting in an increase in the measured diameter of particles. ${ }^{25), 26)}$

The influence of solid content on porosity of the foam ceramic was shown in Fig. 5(d). The porosity of foam ceramic was slowly decreased between $56-62$ mass $\%$ and decreased significantly 62 mass \% later. This is because the plugging take place with the increase of the mullite slurry viscosity leads to the decrease of foam ceramic porosity.

Figure 5(e) shows the influence of solid content on compressive strength of foam ceramic. With the increase of solid content (56-62 mass \%), the compressive strength of foam ceramic was increased quickly and the maximum appeared when the solid content is 62 mass \%. After the solid was above 62 mass $\%$, the compressive strength of foam ceramic declined. This is because the uneven hanging slurry take place due to the high slurry viscosity. During the sintering process, the slurry is only partially sintered and not completely fused, at the same time, the green body cracks due to severe shrinkage. These shortcomings all lead to poor mechanical properties of the final sintered product.

The low sedimentation degree, small particle size and right viscosity of mullite slurry was presented with the optimal process of 62 mass $\%$ of solid content. Under this condition, the porosity of $87 \%$ and optimum compressive strength of 1.42 of mullite foam ceramic was obtained after sintering the as-prepared sample at $1450^{\circ} \mathrm{C}$ for $4 \mathrm{~h}$.

\subsection{Effect of aluminum dihydrogen phos- phate content on performance of slurry and foam ceramic}

Experiments were conducted at solid content of 62 mass $\%$ and ball-milling time of $8 \mathrm{~h}$, respectively. Figure 6(a) reveals the influence of aluminum dihydrogen phosphate content ranged from 5 to 20 mass $\%$ on viscosity of the mullite slurry. As can be seen, the content of aluminum dihydrogen phosphate has a significant influence on viscosity of the mullite slurry, with the increase of aluminum dihydrogen phosphate content (5-12.5 mass \%), the
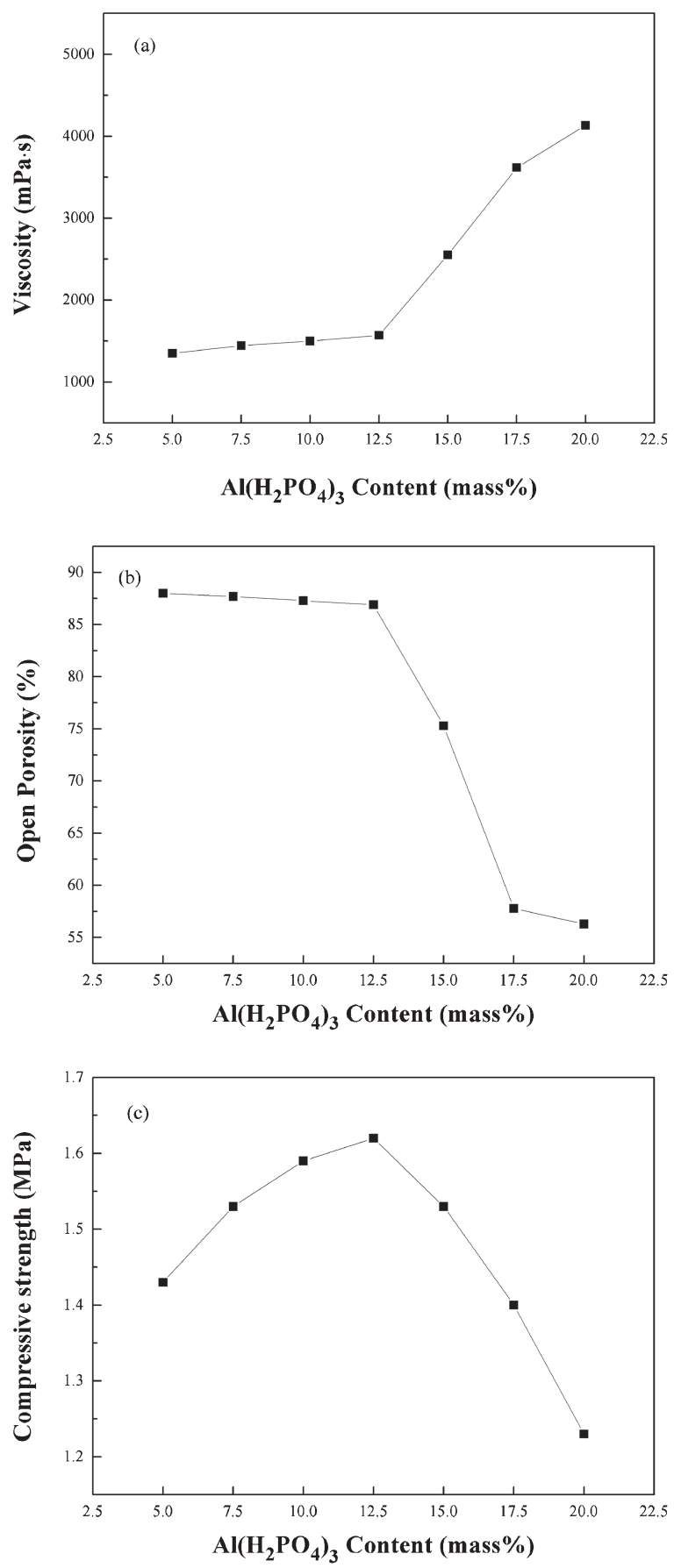

Fig. 6. Influence of $\mathrm{Al}\left(\mathrm{H}_{2} \mathrm{PO}_{4}\right)_{3}$ content on (a) viscosity of mullite slurry and (b) porosity (c) compressive strength of foam ceramic. 
viscosity of mullite slurry was increased slowly and rapidly above 12.5 mass $\%$. The experimental results show that the aluminum dihydrogen phosphate content of 12.5 mass $\%$ should be adopted.

The influence of aluminum dihydrogen phosphate content on open porosity of the foam ceramic was shown in Fig. 6(b). As can be seen, the porosity of foam ceramic reduced slowly with the increase of aluminum dihydrogen phosphate content (5-12.5 mass \%). After 12.5 mass \%, the sharp decrease in porosity of foam ceramic indicates that the viscosity is no longer suitable for impregnation.

Figure 6(c) reveals the influence of aluminum dihydrogen phosphate content on compressive strength of the foam ceramic. As can be seen, the content of aluminum dihydrogen phosphate has a significant influence on compressive strength of the foam ceramic, with the increase of aluminum dihydrogen phosphate content (5-12.5 mass \%), the compressive strength of foam ceramic increased gradually and the maximum value of $1.62 \mathrm{MPa}$ was presented at 12.5 mass $\%$, which is higher than $1.42 \mathrm{MPa}$ compressive strength of foam ceramics without the addition of aluminum dihydrogen phosphate. After 12.5 mass $\%$, the compressive strength quickly declined due to the uneven material distribution causing by high viscosity of the slurry.

The mechanism of the influence of aluminum dihydrogen phosphate on the properties of slurry and ceramics is as follow: Aluminum dihydrogen phosphate monomer reacts slowly with the $\mathrm{Al}_{2} \mathrm{O}_{3}$ in the slurry to form a space network-like structure of aluminum phosphate that crosslinked with other components in the slurry, as shown in Eqs. (3) and (4). ${ }^{27), 28)}$ With the increase of aluminum dihydrogen phosphate content, the bonding strength of the slurry increases due to the increased cross-linking substance in the slurry, leading to the higher compressive strength of ceramic after sintering.

$$
\begin{aligned}
& \mathrm{Al}^{3+}+\mathrm{H}_{2} \mathrm{PO}_{4}^{-}+\mathrm{HPO}_{4}^{2-}+\mathrm{H}_{2} \mathrm{O} \\
& \quad \rightarrow \mathrm{AlH}_{3}\left(\mathrm{PO}_{4}\right)_{2} \cdot \mathrm{H}_{2} \mathrm{O} \\
& \mathrm{Al}_{2} \mathrm{O}_{3}+2 \mathrm{AlH}_{3}\left(\mathrm{PO}_{4}\right)_{2} \cdot \mathrm{H}_{2} \mathrm{O} \\
& \rightarrow 4 \mathrm{AlPO}_{4}+4 \mathrm{H}_{2} \mathrm{O}
\end{aligned}
$$

As the content of aluminum dihydrogen phosphate continue increases, micro-cracks appear on the foam ceramic ribs and gradually increase. This is attributed to the produce of volume shrinkage due to the pyrolysis of aluminum dihydrogen phosphate at high temperature, which causes micro cracks in the framework ribs. ${ }^{29)}$ Therefore, the compressive strength of the ceramic decreases. So the content of aluminum dihydrogen phosphate of 12.5 mass $\%$ was adopt. The pyrolysis reaction equation as follow (5):

$$
\begin{gathered}
\mathrm{Al}\left(\mathrm{H}_{2} \mathrm{PO}_{4}\right)_{3} \stackrel{200-300^{\circ} \mathrm{C}}{\longrightarrow} \text { Amorphous phase } \\
\stackrel{400-500{ }^{\circ} \mathrm{C}}{\longrightarrow} \mathrm{Al}\left(\mathrm{PO}_{3}\right)_{3}+\mathrm{P}_{2} \mathrm{O}_{5} \uparrow
\end{gathered}
$$

The mullite slurry with a viscosity of $1570 \mathrm{mPa} \cdot \mathrm{s}$ was presented under the optimum conditions of 62 mass $\%$ of solid content, 12.5 mass $\%$ of aluminum dihydrogen phos- phate and $8 \mathrm{~h}$ of ball milling time. The $87 \%$ of porosity and $1.62 \mathrm{MPa}$ of compressive strength of foam ceramics were obtained after sintering the as-prepared samples at $1450{ }^{\circ} \mathrm{C}$ for $4 \mathrm{~h}$.

In summary, the optimum condition for preparing the mullite slurry were that, 62 mass $\%$ of solid phase content and 12.5 mass $\%$ of aluminum dihydrogen phosphate content were added into the ball mill tank, then the materials in the ball mill tank were ball milled for $8 \mathrm{~h}$ on a mill grinder at $20^{\circ} \mathrm{C}$. Herein, under the aforedmentioned optimum conditions, an excellent performance slurry with $5 \%$ of RSH, $1570 \mathrm{mPa} \cdot \mathrm{s}$ of viscosity and $7 \mu \mathrm{m}$ of particle $\mathrm{D}_{50}$ can be prepared. Also, the performance of foam ceramic obtained from this kind of slurry after sintering at $1450{ }^{\circ} \mathrm{C}$ for $4 \mathrm{~h}$ was optimum.

\subsection{Characterization results}

Figure 7 displays XRD patterns of the composite sintered at $1200,1300,1400,1450,1500^{\circ} \mathrm{C}$ for $4 \mathrm{~h}$, respectively. As can be seen, the diffraction peaks of mullite (PDF\#73-1512) and corundum (PDF\#10-0394) were observed under all sintering temperatures. With increasing firing temperature from 1200 to $1450{ }^{\circ} \mathrm{C}$, the intensity of characteristic peaks of mullite become stronger due to the more secondary mullitization developed further by the gradual dissolution of corundum into the transitory liquid phase. ${ }^{30), 31)}$ But when the temperature up to $1500^{\circ} \mathrm{C}$, the diffraction peak of mullite phase decreased, this can be attributed to the unstable mullite melting in the glass phase. Thus, the stability of mullite phase depended on the heat treatment temperature. When the temperature reached up to $1450{ }^{\circ} \mathrm{C}$, the stability of mullite phase was obtained.

The SEM micrographs of composite sintered at $1450{ }^{\circ} \mathrm{C}$ for $4 \mathrm{~h}$ were shown in Fig. 8. The SEM analysis revealed a mass of relatively well-developed and interlocked whiskershapes crystals with an aspect ratio of $13.0 \pm 2.9 \mu \mathrm{m}$ with little glass phase are clearly observed. These anisotropic grains lead to the formation of network structure, thus enhance the compressive strength. the SEM-EDS analysis results of the surface of sample sintered at $1450{ }^{\circ} \mathrm{C}$ for $4 \mathrm{~h}$

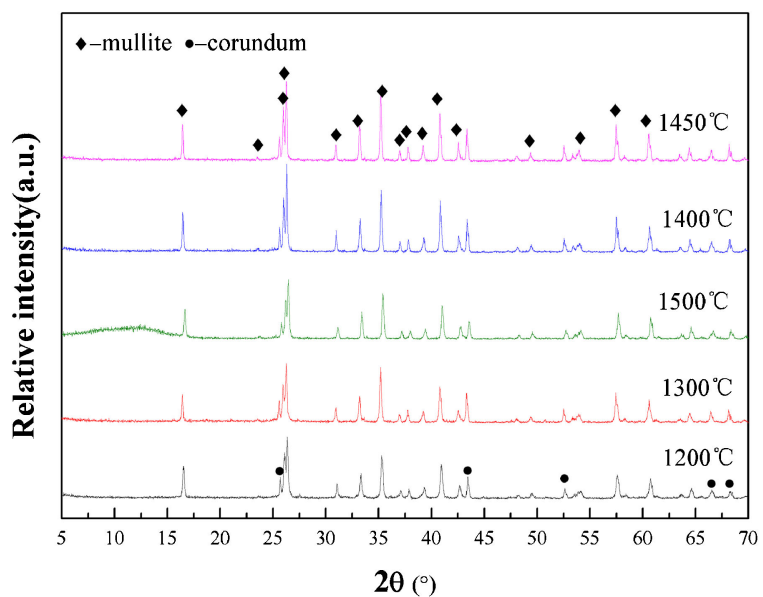

Fig. 7. XRD patterns of the products sintering at different temperature for $4 \mathrm{~h}$. 

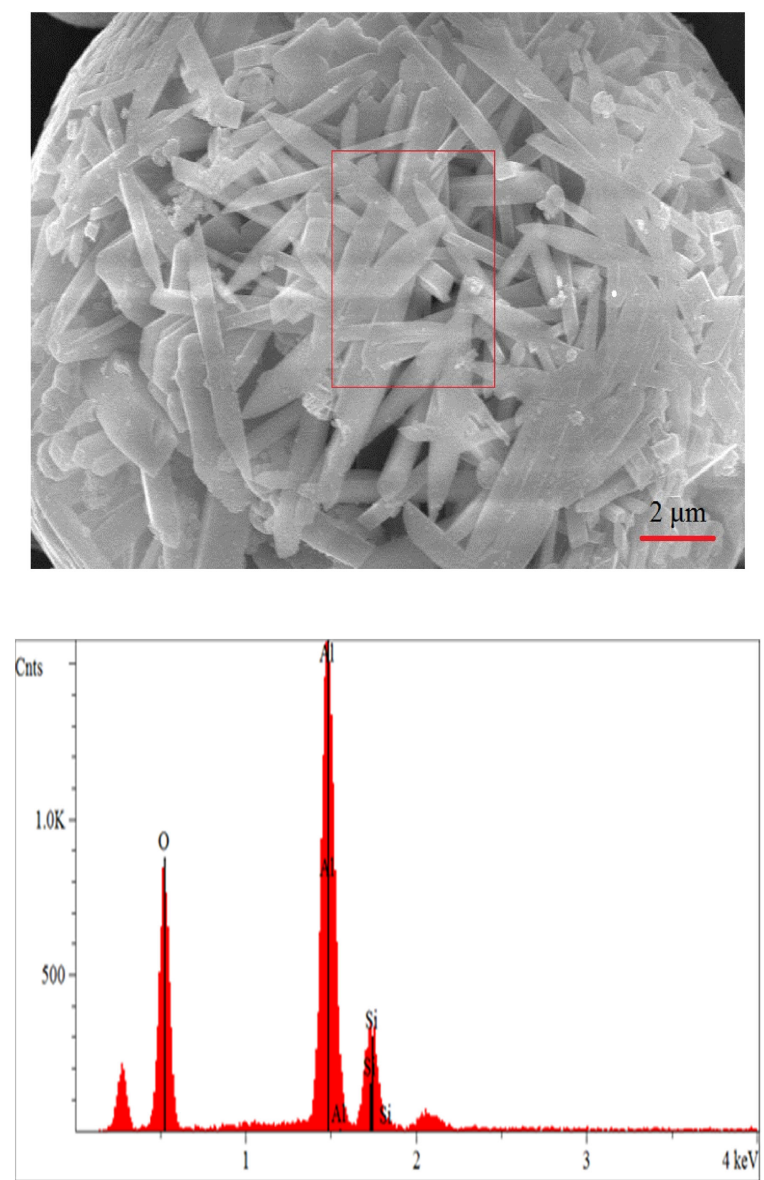

Fig. 8. SEM-EDS micrographs of samples sintered at $1450^{\circ} \mathrm{C}$ for $4 \mathrm{~h}$. Accordingly, the whiskers have the following chemical composition (wt \%): 41.26 O, 44.31 Al, 14.43 Si.

revealed that the mullite whiskers fabricated in the present research show a slightly higher molar ratio of Al to $\mathrm{Si}$ $(\approx 3.20)$ than the theoretical value of 3.0 , which is closed to the molecular components of mullite.

Figure 9 displays the FTIR spectra of mullite foam ceramics sintered at $1200,1300,1400,1450$ and $1500^{\circ} \mathrm{C}$. It can be seen from the figure that the infrared characteristic peaks of ceramics sintered at different temperatures are basically unchanged, the wide band appearing at 445 and $732 \mathrm{~cm}^{-1}$ was due to the vibration of $[\mathrm{SiO} 4]^{4-}$ and $[\mathrm{AlO} 4]^{5-32)}$ At the same time, the bands located at 559 $\mathrm{cm}^{-1}$ was attributed to the vibration of $[\mathrm{AlO} 6]^{9-}$. The components appearing at about $890 \mathrm{~cm}^{-1}$ were attributed to the vitreous phase of raw fly ash while the presence of mullite was responsible for the characteristic bands at $1172 \mathrm{~cm}^{-1} .{ }^{33)}$

Table 2 lists the chemical components of the mullite ceramic sintering at $1450{ }^{\circ} \mathrm{C}$ for $4 \mathrm{~h}$. As can be seen, the total iron content below 0.3 mass $\%$, the sum of $\mathrm{Na}_{2} \mathrm{O}+$ $\mathrm{K}_{2} \mathrm{O}$ was about 0.4 mass $\%, \mathrm{CaO}$ below 0.25 mass $\%$.

\subsection{Physical properties of mullite foam ceramic}

Table 3 lists the physical properties of samples sintered at various temperatures. Obviously, The increase of sin-

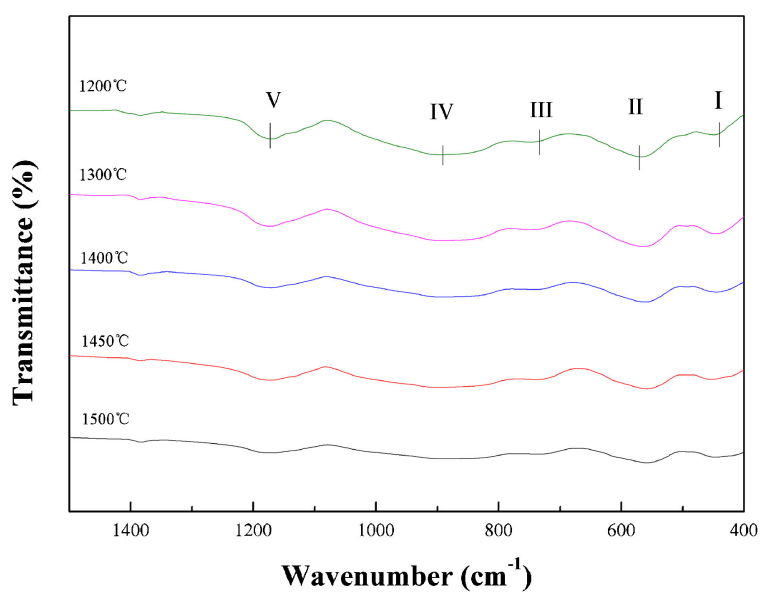

Fig. 9. FTIR spectra of foam ceramic sintered at different temperature (I) Si-O, (II) Al6-O, (III) A14-O, (IV) Al4-O, (V) Si-O.

Table 2. Chemical composition of sintering sample (mass \%)

\begin{tabular}{cccccc}
\hline $\mathrm{Al}_{2} \mathrm{O}_{3}$ & $\mathrm{SiO}_{2}$ & $\mathrm{Fe}_{2} \mathrm{O}_{3}$ & $\mathrm{~K}_{2} \mathrm{O}$ & $\mathrm{Na}_{2} \mathrm{O}$ & $\mathrm{CaO}$ \\
\hline 69.13 & 24.58 & 0.30 & 0.06 & 0.36 & 0.25 \\
\hline
\end{tabular}

tering temperature leads to lower apparent porosity and higher mullite content. A good correlation between compressive strength and apparent porosity was observed, which could be explained by the continuous densification of mullite ceramic leading to stronger binding between the particles with the increase of sintering temperature. Meanwhile, the bridging effect occurs with the growth of mullite whiskers, which can impede ceramic crack propagation when the material is exposed in the suddenly changes environment temperature, leading to the increase of thermal shock resistance of ceramic products. The best compressive strength and thermal shock resistance appeared when the sintering temperature was $1450{ }^{\circ} \mathrm{C}$ for $4 \mathrm{~h}$. When the sintering temperature exceeded $1450^{\circ} \mathrm{C}$, the liquid phasor increased and the strength decreased, in severe cases, the foam ceramics soften and even collapse. In addition, the penetration resistance of water increases as the porosity decreases, leading to the temperature difference between the inside and outside of the ceramic increases in a short time, which results in a reduction in the thermal shock resistance of the ceramic.

Figure 10 shows the surface morphology of the foam ceramic products sintering at $1450^{\circ} \mathrm{C}$ for $4 \mathrm{~h}$. It can be seen, the foam ceramics maintain the morphology of the organic precursor, which have a three-dimensional interconnected grid structure, and the size of the mesh hole in the skeleton is very uniform. This is due to the good rheological properties and stability of the slurry prepared in this experiment.

\section{Conclusion}

In summary, the high performance mullite foam ceramics were prepared with 82 mass \% mullite extracted from high coal fly ash by using organic foam impregnation method. During the process, aluminum dihydrogen phos- 
Table 3. Physical properties of samples sintered at various temperatures for $4 \mathrm{~h}$

\begin{tabular}{ccccc}
\hline $\begin{array}{c}\text { Temperature } \\
\left({ }^{\circ} \mathrm{C}\right)\end{array}$ & $\begin{array}{c}\text { Apparent } \\
\text { porosity } \\
(\%)\end{array}$ & $\begin{array}{c}\text { Mullite } \\
\text { content } \\
(\%)\end{array}$ & $\begin{array}{c}\text { Compressive } \\
\text { strength } \\
(\mathrm{MPa})\end{array}$ & $\begin{array}{c}\text { thermal shock } \\
\text { resistance times }\end{array}$ \\
\hline 1200 & 89.83 & 78.95 & 0.78 & 6 \\
1300 & 87.72 & 80.63 & 0.96 & 8 \\
1400 & 86.78 & 83.32 & 1.32 & 9 \\
1450 & 86.62 & 87.73 & 1.62 & 13 \\
1500 & 79.14 & 87.12 & 1.18 & 8 \\
\hline
\end{tabular}

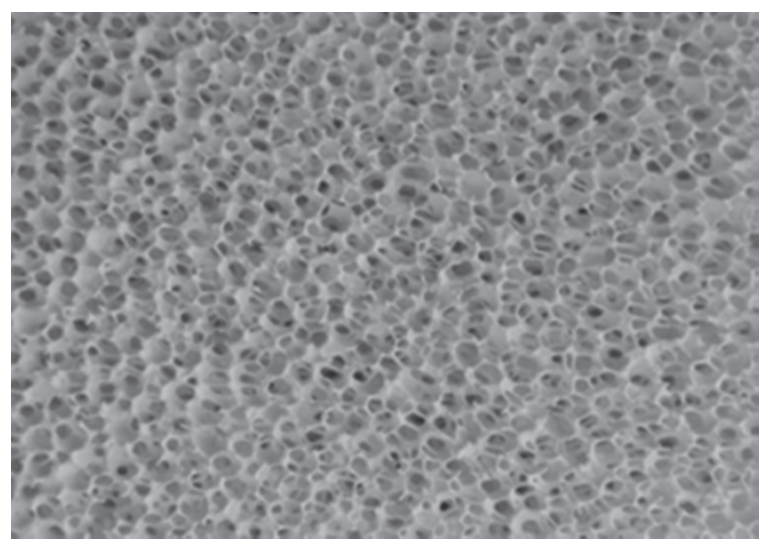

Fig. 10. Photograph of mullite foam ceramics.

phate and kaolin were used as bonding reagent and plasticizer, respectively. Firstly, a high-quality slurry with low sedimentation degree, suitable viscosity and small mullite particle $\mathrm{D}_{50}$ can be prepared under the condition of phosphate content of 12.5 mass $\%$, solid phase content of 62 mass $\%$ and ball-milling time of $8 \mathrm{~h}$. Then, the high performance mullite foam ceramics with apparent porosity of $87 \%$, compressive strength of $1.62 \mathrm{MPa}$ and thermal shock resistance of 13 times were obtained by sintering at $1450{ }^{\circ} \mathrm{C}$ for $4 \mathrm{~h}$, respectively, which was comparable with previous reports. This method provides a potential way on the utilization of coal fly ash to prepare mullite foam ceramic product.

Acknowledgement This work was supported by the Major Scientific and Technological Projects of Inner Mongolia, China (No.20141806).

\section{References}

1) K. Martinello, M. L. Oliveira, F. A. Molossi, C. G. Ramos, E. C. Teixeira, R. M. Kautzmann and L. F. Silva, Sci. Total Environ., 470-471, 444-452 (2014).

2) M. Izquierdo and X. Querol, Int. J. Coal Geol., 94, 5466 (2012)

3) L. Zhou, Y. L. Chen, X. H. Zhang, F. M. Tian and Z. N. $\mathrm{Zu}$, Mater. Lett., 119, 140-142 (2014).

4) M. G. Zhu, R. Ji, Z. M. Li, H. Wang, L. L. Liu and Z. T. Zhang, Constr. Build. Mater., 112, 398-405 (2016).
5) B. Chen, Z. Luo and A. Lu, Mater. Lett., 65, 3555-3558 (2011).

6) Y. M. Park, T. Y. Yang, S. Y. Yoon, R. Stevens and H. C. Park, Mater. Sci. Eng. A, 454-455, 518-522 (2007).

7) Y. Dong, X. Feng, X. Feng, Y. Ding, X. Liu and G. Meng, J. Alloy. Compd., 460, 599-606 (2008).

8) J. H. Li, H. W. Ma and W. H. Huang, J. Hazard. Mater, 166, 1535-1539 (2009).

9) H. S. Guo, W. F. Li and F. B. Ye, Ceram. Int., 42, 17332-17338 (2016).

10) L. Xu, X. Xi, W. Zhu, A. Shui and W. Dai, J. Alloy. Compd., 649, 739-745 (2015).

11) M. Srivastava, M. Muniprakash and S. K. Singh, Surf. Coat. Tech., 245, 148-155 (2014).

12) M. Fu, J. Liu, X. F. Dong, L. Zhu, Y. C. Dong and S. Hampshire, J. Eur. Ceram. Soc., 39, 5320-5331 (2019).

13) C. X. Li, Y. Zhou, Y. M. Tian, Y. Y. Zhao, K. Y. Wang, G. M. Li and Y. S. Chai, Ceram. Int., 45, 5613-5616 (2019).

14) B. Y. Ma, C. Su, X. M. Ren, Z. Gao, F. Qian, W. G. Yang, G. Q. Liu, H. X. Li, J. K. Yu and Q. Zhu, J. Alloy. Compd., 803, 981-991 (2019).

15) J. S. Lu, Z. P. Zhang, Y. D. Li and Z. Y. Liu, Constr. Build. Mater, 229, 116851 (2019).

16) C. ThyeFoo, M. A. MohdSalleh, K. K. Ying and K. AminMatori, Ceram. Int., 45, 7488-7494 (2019).

17) M. L. Bouchetou, J. P. Ildefonse, J. Poirierab and P. Daniellouc, Ceram. Int., 31, 999-1005 (2005).

18) J. B. Zhang, H. q. Li, S. P. Li, P. P. Hu, W. F. Wu, Q. S. Wu and X. G. Xi, Ceram. Int., 44, 3884-3892 (2018).

19) S. S. T. Gao, Y. F. Zhang, Y. M. Zhang, S. B. Sun and M. J. Wang, J. Ceram. Soc. Jpn., 127, 90-97 (2019).

20) R. David, Eur. Rubber J., 179, 25-27 (1997).

21) Z. D. Pan, J. X. Li and C. Yan, J. Ceram., 22, 263-267 (2001). [in Chinese].

22) S. X. Ji and B. K. Gong, China Ceramic, 44, 50-53 (2008) [in Chinese].

23) J. Huang, J. Z. Zhang, Y. Zhang and X. Shi, China Foundry, 65, 175-178 (2016).

24) L. V. Woodcock, Nature, 385, 141-143 (1997).

25) M. Fukushima, Y. Zhou and Y. I. Yoshizawa, Mater. Sci. Eng., 148, 211-214 (2008).

26) L. Xiong, X. R. Liu and J. M. Ni, J. Cent. South Univ., 39, 765-770 (2008).

27) A. S. Wagh, S. Grover and S. Y. Jeong, J. Am. Ceram. Soc., 86, 1845-1849 (2003).

28) H. J. Han and D. P. Kim, J. Sol-Gel Sci. Technol., 26, 223-228 (2003).

29) J. H. Morris, P. G. Perkins, A. E. A. Rose and W. E. Smith, Chem. Soc. Rev., 11, 173-194 (1977).

30) C. Y. Chen, G. S. Lan and W. H. Tuan, J. Eur. Ceram. Soc., 20, 2519-2525 (2000).

31) M. A. Sainz, F. J. Serrano, J. M. Amigo, J. Bastida and A. Caballero, J. Eur. Ceram. Soc., 20, 403-412 (2000).

32) R. P. Penilla, A. G. Bustos and S. G. Elizalde, J. Am. Ceram. Soc., 86, 1527-1533 (2003).

33) M. Criado, A. F. Jiménez and A. Palomo, Micropor. Mesopor. Mat., 106, 180-191 (2007). 